Blood Purification in Intensive Care

This book has been made possible by the generous support of Edwards Life Sciences. 


\section{Contributions to Nephrology}

Vol. 132

Series Editors

G.M. Berlyne Beersheva/Brooklyn, N.Y.

C. Ronco Vicenza

KARGER 
Proceedings of the Second International Course on Critical Care Nephrology,

Vicenza, May 22-25, 2001

\title{
Blood Purification in Intensive Care
}

\author{
Volume Editors \\ C. Ronco Vicenza \\ R. Bellomo Melbourne, Vic. \\ G. La Greca Vicenza
}

69 figures, 19 in color, and 49 tables, 2001

\footnotetext{
KARG R Basel· Freiburg $\cdot$ Paris $\cdot$ London $\cdot$ New York .

New Delhi $\cdot$ Bangkok $\cdot$ Singapore $\cdot$ Tokyo $\cdot$ Sydney
} 


\section{Claudio Ronco}

Department of Nephrology

St. Bortolo Hospital

I-36100 Vicenza (Italy)

\section{Giuseppe La Greca}

Department of Nephrology

St. Bortolo Hospital

I-36100 Vicenza (Italy)

\section{Rinaldo Bellomo}

Intensive Care Unit

Austin \& Repatriation Medical Center

Melbourne, Vic. 3084 (Australia)

Library of Congress Cataloging-in-Publication Data

International Course on Critical Care Nephrology (2nd : 2001 ; Vicenza, Italy)

Blood purification in intensive care : proceedings of the Second International Course on Critical Care Nephrology, Vicenza, May 22-25, 2001 / volume editors, C. Ronco, R. Bellomo, G. La Greca.

p. cm. - (Contributions to nephrology, ISSN 0302-5144; vol. 132)

ISBN 3805572027 (hard cover : alk. paper)

1. Acute renal failure-Congresses. 2. Renal intensive care-Congresses.

3. Blood-Filtration-Congresses. 4. Hemodialysis-Congresses. 5. Artificial kidney-Congresses.

I. Ronco, C. (Claudio), 1951- II. Bellomo, R. (Rinaldo), 1956- III. La Greca, G. (Giuseppe). IV. Title.

V. Contributions to nephrology; v. 132.

RC918.R4 I515 2001

$616.6^{\prime} 14-\mathrm{dc} 21$

2001029339

Bibliographic Indices. This publication is listed in bibliographic services, including Current Contents ${ }^{\circledR}$ and Index Medicus

Drug Dosage. The authors and the publisher have exerted every effort to ensure that drug selection and dosage set forth in this text are in accord with current recommendations and practice at the time of publication. However, in view of ongoing research, changes in government regulations, and the constant flow of information relating to drug therapy and drug reactions, the reader is urged to check the package insert for each drug for any change in indications and dosage and for added warnings and precautions. This is particularly important when the recommended agent is a new and/or infrequently employed drug.

All rights reserved. No part of this publication may be translated into other languages, reproduced or utilized in any form or by any means, electronic or mechanical, including photocopying, recording, microcopying, or by any information storage and retrieval system, without permission in writing from the publisher.

CC Copyright 2001 by S. Karger AG, P.O. Box, CH-4009 Basel (Switzerland)

www.karger.com

Printed in Switzerland on acid-free paper by Reinhardt Druck, Basel

ISSN 0302-5144

ISBN 3-8055-7207-7 


\section{Contents}

IX Preface

Ronco, C. (Vicenza); Bellomo, R. (Melbourne, Vic.); La Greca, G. (Vicenza)

Epidemiology and Pathogenesis of ARF in ICU

1 Incidence of Acute Renal Failure in the Intensive Care Unit Vincent, J.L. (Brussels)

7 Pathophysiology of Ischemic Acute Renal Failure Sheridan, A.M.; Bonventre, J.V. (Charlestown, Mass.)

22 Risk Factors for Acute Renal Failure in the Intensive Care Unit Piccinni, P.; Lieta, E.; Marafon, S. (Vicenza)

ARF and Multiple Organ Failure

26 The Kidney in Shock

Thijs, L.G. (Amsterdam)

41 Molecular Mechanisms Underlying Combined Kidney-Lung Dysfunction during Acute Renal Failure

Rabb, H.; Chamoun, F. (Minneapolis, Minn.); Hotchkiss, J. (St. Paul, Minn.)

53 Thrombotic Microangiopathies in the Intensive Care Unit: Many Questions, Some Answers

Ruggenenti, P.; Aros, C.; Remuzzi, G. (Bergamo)

ARF and Diagnostic Procedures in ICU

68 Role of the Renal Biopsy in Acute Renal Failure

Solez, K. (Edmonton, Alta.); Racusen, L.C. (Baltimore, Md.)

76 Imaging Techniques in Acute Renal Failure

Pozzi Mucelli, R.; Bertolotto, M.; Quaia, E. (Trieste) 
92 Hemodynamic Monitoring in the ICU

Pinsky, M.R. (Pittsburgh, Pa.)

114 Transesophageal Echocardiography in the ICU

Dan, M. (Vicenza); Sorbara, C. (Padua)

Conservative Management of ARF

136 Antibiotic Therapy in Acute Renal Failure Benedetti, P.; de Lalla, F. (Vicenza)

146 The Renal Effects of Noradrenaline and Dopamine Bellomo, R. (Melbourne, Vic.); Ronco, C. (Vicenza)

158 The Role of Diuretic Agents in the Management of Acute Renal Failure Venkataram, R.; Kellum, J.A. (Pittsburgh, Pa.)

Renal Replacement Therapy in ICU

171 Renal Replacement Therapy (RRT) in the ICU: Criteria for Initiating RRT Burchardi, H. (Göttingen)

181 Severity Scores and Outcomes with Acute Renal Failure in the ICU Setting

Paganini, E.P.; Larive, B.; Kanagasundaram, N.S. (Cleveland, Ohio)

196 Answers from the First International Course on Critical Care Nephrology Questionnaire

Ronco, C.; Zanella, M.; Brendolan, A.; Milan, M.; Zamperetti, N. (Vicenza);

Bellomo, R. (Melbourne, Vic.)

Which Treatment for ARF in ICU?

210 Peritoneal Dialysis in Acute Renal Failure of Adults: The Safe, Effective, and Low-Cost Modality

Ash, S.R. (West Lafayette, Ind. )

222 Selected Practical Aspects of Intermittent Hemodialysis in Acute Renal Failure Patients

Dhondt, A.; Van Biesen, W.; Vanholder, R.; Lameire, N. (Ghent)

236 Continuous Renal Replacement Techniques

Ronco, C.; Brendolan, A. (Vicenza); Bellomo, R. (Melbourne, Vic.)

252 Hybrid Renal Replacement Modalities for the Critically III

Marshall, M.R. (Auckland); Golper, T.A. (Nashville, Tenn.); Shaver, M.J.;

Chatoth, D.K. (Little Rock, Ark.) 
258 Acute Dialysis Quality Initiative (ADQI)

Kellum, J.A. (Pittsburgh, Pa.); Mehta, R.L. (San Diego, Calif.); Ronco, C. (Vicenza)

CRRT: Practical Aspects

266 Vascular Access for Extracorporeal Renal Replacement Therapies in the Intensive Care Unit in Clinical Practice

Canaud, B.; Martin, K.; Nguessan, C.; Klouche, K.; Leray-Loragues, H.; Béraud, J.J. (Montpellier)

283 Anticoagulation in Continuous Renal Replacement Therapy

Schetz, M. (Leuven)

304 Factors Influencing Therapy Delivery in Acute Dialysis

Clark, W.R. (McGaw Park, Ill./Indianapolis, Ind.); Ronco, C. (Vicenza)

313 Dialysate and Substitution Fluids for Patients Treated by Continuous Forms of Renal Replacement Therapy

Davenport, A. (London)

323 Machines for Continuous Renal Replacement Therapy

Ronco, C.; Brendolan, A.; Dan, M.; Piccinni, P. (Vicenza); Bellomo, R.

(Melbourne, Vic.)

ARF and Sepsis

335 Fluid Management in CRRT

Mehta, R.L. (San Diego, Calif.)

349 Update on Drug Sieving Coefficients and Dosing Adjustments during Continuous Renal Replacement Therapies

Golper, T.A. (Nashville, Tenn.)

354 Sepsis: A Pro- and Anti-Inflammatory Disequilibrium Syndrome Pinsky, M.R. (Pittsburgh, Pa.)

367 Extracorporeal Blood Purification Therapy for Sepsis and Systemic Inflammation: Its Biological Rationale

Bellomo, R.; Baldwin, I. (Melbourne, Vic.); Ronco, C. (Vicenza)

New Trends in CRRT

375 High-Volume Hemofiltration

Bellomo, R.; Baldwin, I. (Melbourne, Vic.); Ronco, C. (Vicenza)

383 Coupled Plasma Filtration Adsorption in the Treatment of Septic Shock Brendolan, A. (Vicenza); Bellomo, R. (Melbourne, Vic.); Tetta, C. (Mirandola); Piccinni, P.; Digito, A. (Vicenza); Wratten, M.L. (Mirandola); Dan, M.; Irone, M.; La Greca, G. (Vicenza); Inguaggiato, P. (Mirandola); Ronco, C. (Vicenza) 
391 Plasmapheresis in Sepsis

Berlot, G.; Lucangelo, U.; Galimberti, G. (Trieste); Sganga, G. (Rome)

400 Should We Target Signal Pathways Instead of Single Mediators in the Treatment of Sepsis?

Wratten, M.L. (Mirandola); Brendolan, A.; Ronco, C.; La Greca, G. (Vicenza); Tetta, C. (Mirandola)

415 Endotoxin Removal by Toraymyxin

Kunitomo, T.; Shoji, H. (Tokyo)

421 Author Index

422 Subject Index 


\section{Preface}

Major changes have taken place in the practice of critical care medicine and nephrology in the last 20 years. The same is true in the field of extracorporeal blood purification. Critical care medicine is today an established medical specialty with specific therapies, publications, practical and cognitive skills, and procedures. The development of intensive care units has had major implications for the kind of surgery that can be performed routinely (coronary artery bypass surgery) and for the kind of patients (elderly and with significant chronic diseases) that can be successfully treated. The evolution of critical care medicine has also had significant implications for clinical nephrology. One of the most important aspects is related to the nature, epidemiology and management of severe acute renal failure (ARF).

Severe ARF is now profoundly different from the disease seen by nephrologists 20 years ago: it is seen predominantly in intensive care units, is usually associated with the dysfunction of other organs, is often accompanied by sepsis, is typically multifactorial, and has a very high mortality. Management of this type of ARF demands the application of complex knowledge and skills. Such knowledge and skills can only come from either a multidisciplinary approach in which nephrologist and intensivist work side by side to achieve optimal care for a given patient, or from specialists originally from either field who have gone on to formally acquire expertise and training in both specialties.

Such an approach has led to the development of an area defined as Critical Care Nephrology. The common ground for such an integrated approach has been represented by extracorporeal renal replacement therapies. Although born in the nephrologic environment for end-stage renal disease patients, they rapidly grew as an important family of treatments for acute patients. This in particular has been the case with continuous rernal replacement therapies (CRRT). 
The use of CRRT has partly redefined the indications for initiating dialytic therapy in the intensive care unit; it has expanded the possible role of blood purification in the management of critically ill patients, and has widened the scope of interaction between the expertise of the nephrologist, the needs of the intensivist, and their common goals for patient recovery.

In the present book we collect the contributions of several experts in the field and aim at generating a comprehensive review of the different blood purification techniques today required and performed in the intensive care unit. The aim of this volume of the Contributions to Nephrology series is to provide the scientific community with some of the latest contributions in the field of blood purification techniques and multiple organ failure giving a balanced mix between established knowledge and newer results from clinical trials and basic research. We were able to put together an outstanding group of scientists and clinicians involved in the treatment of critically ill patients with multiple organ failure and are sincerely indebted with all who made possible this publication.

We hope this book will serve as a tool for consultation and informative reading for all professionals involved in the care of the critically ill patient.

Claudio Ronco

Rinaldo Bellomo

Giuseppe La Greca 